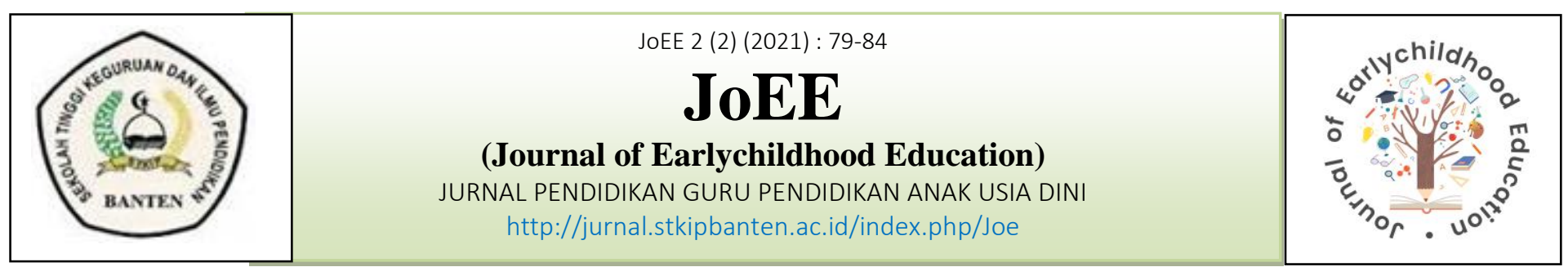

\title{
PENGGUNAAN PLASTISIN UNTUK MENINGKATKAN PERKEMBANGAN MOTORIK HALUS ANAK USIA DINI KELOMPOK B DI TK AL FIRMANSYAH
}

\author{
Nia Kurniasih ${ }^{1}$, Destri Astrianingsih ${ }^{2}$, dan Iis Sholehah ${ }^{3}$ \\ ${ }^{1}$ Sekolah Tinggi Keguruan dan Ilmu Pendidikan Banten \\ ${ }^{2}$ Sekolah Tinggi Keguruan dan Ilmu Pendidikan Banten \\ ${ }^{3}$ Mahasiswa Pendidikan Guru Pendidikan Anak Usia Dini \\ Penulis Korespondensi:, niakurniasih743@ gmail.com ${ }^{1}$, destriastria@ gmail.com², \\ iissholehah.cikande@gmail.com ${ }^{3}$ \\ Artikel: Perkembangan Motorik Halus Anak Usia Dini \\ Penerima: Juli 2021 \\ Diterima: Agustus 2021 \\ Dipublikasikan: September 2021
}

\begin{abstract}
Plasticine is a type of game that requires fine motor skills and requires a high creativity, fine motor skills are movement that involve certain body part carried out by small (smooth) muscles. This study aims to determine the fine motor development of children by using plasticine media in group $B$ of kingdengarten AL Firmansyah. This research is a classroom action research, with a qualitative description research type. The data collection tools use the methods of observation. Interviews, and documentation studies. The research subject is totaling 9 children consisting of 5 girls and 4 boys. Based on the result of the study, it was shown that the plasticine media can improve the fine motor development of early childhood. From the two cycles activities, the study obtained very significant result, namely increasing the fine motor development of children in cycle one as much as 44,4\% of presentage of children with BSH criteria of 3 children, BSH 1 child, and cycle two by 77,7\% of the prestation of children with the criteria of BSH 3 children and BSB 4 children based on these result, it can be concluded that plastiticine media can improve the fine motor development of children in group B at kingdengarten Al Firmansyah cikande wit very satysfing result.
\end{abstract}

Keyword : Plasticine Media, Fine Motoric Development

\begin{abstract}
ABSTRAK
Plastisin merupakan suatu jenis permainan yang membutuhkan keahlian motorik halus dan membutuhkan suatu kreativitas yang tinggi, motorik halus adalah gerakan yang melibatkan bagian tubuh tertentu yang di lakukan oleh otot-otot kecil (halus). Penelitian ini bertujuan untuk mengetahui perkembangan motorik halus anak dengan menggunakan media plastisin di kelompok B TK Al Firmansyah. Penelitian ini merupakan penelitian tindakan kelas dengan jenis penelitian deskripsi kualitatif. Adapun alat pengumpulan datanya menggunakan metode observasi, wawancara dan studi dokumentasi.Dengan subjek penelitian yaitu berjumlah 9 anak yang terdiri dari 5 anak perempuan dan 4 anak laki-laki. Berdasarkan
\end{abstract}


Nia Kurniasih, Destri Astrianingsih, dan Iis Sholehah: Penggunaan Plastisin Untuk Meningkatkan

Perkembangan Motorik halus Anak Usia Dini kelompok B di Tk Al Firmansyah

hasil penelitian menunjukan bahwa media plastisin dapat meningkatkan perkembangan motorik halus anak usia dini. Dari kegiatan dua siklus tersebut peneliti mendapatkan hasil yang sangat signifikan, yaitu meningkatnya perkembangan motorik halus anak pada siklus I sebanyak 44,4\% dari presentasi anak dengan kriteria BSH 3 anak, BSB 1 anak, dan siklus II sebesar 77,7\% dari presentasi anak dengan kriteria BSH 3 anak dan BSB 4 anak. Berdasarkan hasil tersebut, maka dapat penulis simpulkan bahwa media plastisin dapat meningkatkan perkembangan motorik halus anak pada siswa kelompok B di Tk Al Firmansyah cikande dengan hasil yang sangat memuaskan.

Kata kunci: Media Plastisin, Perkembangan Motorik Halus.

\section{PENDAHULUAN}

Pendidikan taman kanak-kanak (TK) merupakan salah satu bentuk pendidikan anak usia dini yaitu anak yang berusia empat sampai enam tahun. Pendidikan TK memiliki peran yang sangat penting untuk mengembangkan kepribadian anak serta mempersiapkan mereka untuk memasuki jenjang pendidikan selanjutnya. Froebel memandang pendidikan dapat membantu perkembangan anak secara wajar. Ia menggunakan taman sebagai simbol dari pendidikan anak. Apabila anak mendapatkan pengasuhan yang tepat,maka seperti halnya taman yang muda, anak akan berkembang secara yang wajar mengikuti hukumnya sendiri. Pendidikan TK harus mengikuti sifat dan karakter anak. Seperti halnya Froebel Montessori beranggapan bahwa pendidikan merupakan suatu upaya untuk membantu perkembangan anak secara menyeluruh dan bukan sekedar mengejar.

Pendidikan anak usia dini pada hakikatnya adalah pendidikan yang di selenggarakan dengan tujuan untuk memfasilitasi pertumbuhan dan perkembangan anak secara menyeluruh atau menekan pada perkembangan seluruh

aspek kepribadian anak. Pendidikan anak usi dini member kesempatan kepada anak untuk mengembangkan kepribadiannya. Oleh karena itu, pendidikan untuk anak usia dini khususnya TK perlu menyediakan berbagai kegiatan yang dapat mengembangkan berbagai aspek perkembangan yang meliputi kognitif, bahasa, social, emosi, fisik, dan motorik.

Hal yang di senada di kemukakan oleh Yudha dan Rudyanto yang di kutip olehimam musbikin (2012): menyatakan bahwa motorik halus adalah kemampuan anak beraktifitas dengan menggunakan otot halus (kecil) seperti menulis, menggambar, menyusun balok dan memasukan kelereng. Berdasarkan hasil wawancara dengan guru TK Al firmansyah mengenai perekambangan motorik halus anak usia dini di Tk Al Firmansyah bahwasanya di ketahui dalam proses pembelajaran motorik halusnya hanya dengan menggambar, mewarnai, menjiplak, menggunting, Sehingga perkembangan motorik halusnya pun kurang sepenuhnya meningkat. Salah satu media yang dapat di gunakan untuk meningkatkan kemampuan motorik halus anak ialah media plastisin.

Media plastisin adalah bahan terbaik yang di gunakan untuk belajardengan anak-anak.Kebanyakan anak-anak menemukan bahwa tekstur dari lilin itu sendiri yang menyenangkan untuk di sentuh dan di manipulasi atau di rubah. Ini amatlah mudah untuk di bentuk sesuatu dengan lilin dan merubahnya menjadi bentuk, ukuran,dan tampilan yang lain Igrea Siswanto (2012), Kebanyakan anakanak telah siap memakai lilindan mereka asik dalam perasaan,memukul-mukul lilin,menekan lilin,melumpuri lilin,dan memotong lilin. Mereka memperoleh 
tentang pengalaman yang menyenangkan dan memuaskan.

Menurut Lilis Krisnawati (2008) kegiatan media plastisin adalah kegiatan yang di lakukan dengan cara membentuk, mewarnai, dan memberwarna sehingga menimbulkan bentuk. Kegiatan media plastisin seperti halnya menyanyi dapat di lakukan dengan kesadaran penuh berupa maksud dan tujuan tertentu maupun sekedar membuat bentuk tanpa arti.

Berdasarkan hasil observasi yang di lakukan di TK Al firmansyah dapat di ketahui bahwa terdapat permasalahan terhadap kemampuan motorik halus anak yang belum sepenuhnya meningkat, respon anak terhadap proses pembelajaran masih kurang, media yang di gunakan kurang bervariasi, kurang nya kegiatan yang menstimulasi kemampuan motorik halus dari guru, oleh karena itu perkembangan motorik halusnya pun kurang begitu signifikan.

Berdasarkan uraian di atas hasil dari indikator yang di nilai dalam hasil observasi yaitu menggunting pola garis lurus, melakukan gerakan yang rumit, menjiplak bentuk tangan. Adapun jumlah anak 9 yang di amati maka di peroleh hasil yang belum berkembang sebanyak 6 anak, dan yang mulai berkembang sebanyak 1 anak, berkembang sesuai harapan 1 anak dan yang berkembang sangat baik 1 anak. Berdasarkan temuan permasalahanpermasalahn tersebut dan mengingat betapa pentingnya mengembangkan kemampuan motorik halus bagi keberhasilan anak di masa yang akan datang maka perlu diadakan upaya meningkatkan perkembangan motorik halus anak sejak dini.

Salah satu media pembelajaran yang dapat di terapkan dalam meningkatkan kemampuan motorik halus adalah dengan media plastisin. Plastisin adalah mainan anak-anak yang bersifat lunak dan merupakan benda padat yang dapat di tekan dan di bentuk sesuai keinginan kita, media plastisin juga sangat mudah untuk di bentu-bentuk dan plastisin juga aman untuk anak-anak,.

Kurangnya kemampuan motorik halus anak di TK Al Firmansyah, banyak anak- anak yang belum bisa sepenuhnya percaya diri dikarenakan kurangnya bermain yang bernuasa edukatif. Jika motorik halus anak di abaikan maka akan berdampak di jenajang berikutnya dalam tahapan menulis, keterampilan motorik halus sangatlah penting dalam kehidupan anak dan dapat secara langsung mempengaruhi rasa percaya diri anak di sekolah.

Tujuan peneliti ini adalah untuk mengetahui perkembangan motorik halus anak dengan menggunakan media plastisin di TK Al Firmansyah.

\section{LANDASAN TEORI}

Media plastisin adalah suatu media yang terbuat dari tepung, minyak, garam. Pewarna makanan dan air sehingga sangat mudah di gunakan karena plastisin olahan barang lunak yang dapat di remas-remas, di pipihkan, di Tarik-tarik, di tekan-tekan. di gulung-gulung dan biasa di bentuk sesuai dengan imajinasi dan keinginan anak.

Menurut sujiono (2013), motorik halus adalah gerakan yang melibatkan bagian-bagian tubuh tertentu yang di lakukan oleh otot-ototkecil (halus) serta memerlukan koordinasi yang cermat. Seperti menggunting, menulis, meremas, menggenggam, menggambar, menyusun balok, meronce dan lain-lain.

\section{METODE PENELITIAN}

Metode yang di gunakan dalam penelitian ini adalah metode penelitan tindakan kelas. PTK merupakan salah satu bentuk kajian yang bersifat reflektif oleh pelaku Tindakan yang di lakukan sematamata untuk meningkatkan kemampuan 
Nia Kurniasih, Destri Astrianingsih, dan Iis Sholehah: Penggunaan Plastisin Untuk Meningkatkan

Perkembangan Motorik halus Anak Usia Dini kelompok B di Tk Al Firmansyah

rasional dari tindakan-tindakan yang di lakukan yaitu definisi PTK menurut Hamzah B. Uno.

Adapun model PTK ini menggunakan PTK yang di kembangkan oleh kemmis dan mc taggert. Dalm model ini memiliki empat komponen yaitu perencanaan (planning). Pelaksanaan (implementation), observasi (observating). Refleksi ( reflecting ). Alasan pemilihan model penelitian yang di kembangkan oleh kemmis dan mc taggart, karena pada model kemmis dan taggart Tindakan. Dan observasi dilakukan dalam satu kegiatan untuk memperbaiki proses pembelajaran di dalam kelas.

Adapun dalam bagan model kemmis dan me taggart digambarkan sebagai berikut:

\section{Rangkaian}

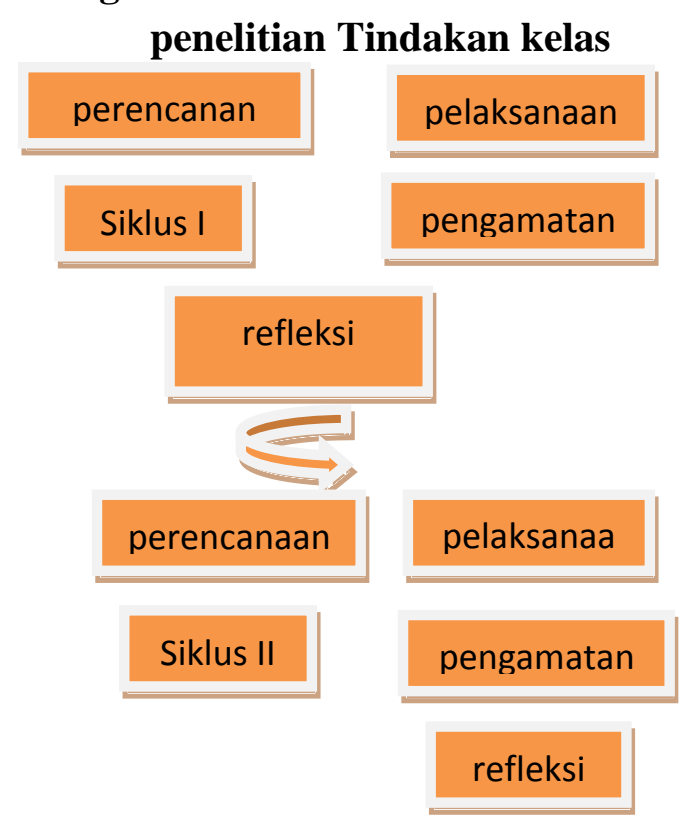

\section{HASIL DAN PEMBAHASAN}

\section{Hasil}

Adapun hasil siklus I perkembangan motorik halusnya meningkat akan tetapi . belum mencapai indikator keberhasilan.Hasil pada siklus II mengalami peningkatan BSB 4 anak, (C) 2021, JoEE, Jurnal of Early Childhood. PGPAUD e-ISSN: 2775-7870
BSH 3 anak, MB 2 anak dan BB 0 anak. Adapun hasil penelitian pada siklus II ini telah terlaksana dengan baik sehingga mendapatkan hasil yang lebih dari indikator keberhasilan yang di tentukanyaitu $75 \%$.

\section{Tabel}

Perkembangan presentasi peserta didik Siklus I dan siklus II

\begin{tabular}{|c|c|c|c|c|c|}
\hline \multirow{2}{*}{$\begin{array}{c}\text { Sik } \\
\text { lus }\end{array}$} & \multicolumn{4}{|c|}{$\begin{array}{c}\text { Hasil penilaian } \\
\text { peningkatan motorik } \\
\text { halus }\end{array}$} & $\begin{array}{c}\text { Total } \\
\text { hasil } \\
\text { pening } \\
\text { katan }\end{array}$ \\
\cline { 2 - 5 } & BB & MB & $\begin{array}{c}\text { BS } \\
\text { H }\end{array}$ & $\begin{array}{c}\text { BS } \\
\text { B }\end{array}$ \\
\hline Sik & 2 & 3 & 3 & 1 & $44,4 \%$ \\
lus & $(22$, & $(33$, & $(33$, & $(11$, & \\
I & $2 \%)$ & $3 \%)$ & $3 \%)$ & $1 \%)$ & \\
\hline Sik & & 2 & 3 & 4 & $77,7 \%$ \\
lus & $0 \%$ & $(22$, & $(33$, & $(44$, & \\
II & \multicolumn{7}{|c|}{$2 \%)$} & $3 \%)$ & $4 \%)$ & \\
\hline \multicolumn{7}{|c|}{ Indikator keberhasilan } & $75 \%$ \\
\hline
\end{tabular}

\section{Pembahasan}

Pada penelitian tindakan kelas di lakukan pada anak kelompok B TK Al firmansyah di kecamatan Cikande kota Serang di laksanakan dalam 2 siklus. Siklus I dan siklus II masing-masing di lakukandalam 2x pertemuan.Siklus I di laksanakan pada hari rabu dan kamis 04-05 agustus 2021, siklus II di laksanakan pada hari rabu dan kamis tanggal 11-12 agustus 2021. Jumlah anak yang menjadi subjek penelitian yaitu sebanyak 9 orang anak yang terdiri dari 5 perempuan dan 4 anaklaki-laki.

Pada pertemuan pertama dan pertemuan kedua anak belum memahami tentang tata cara pembuatan bentuk bulan dan bintang, karena terbukti dari jumlah 9 anak dari hasil pembelajarannnya yang PGPAUD JURNAL 
belum tuntas terdapat 5 anak, dan anak pun terlihat bingung dalam pembuatannya dan anak anak berkata "ibu guru saya belum bisa" dalam pembelajarannya guru membuat dua kelompok satu kelompok laki- laki dan 1 kelompok perempuan, guru memberikan alas pada lantai untuk pembelajarannya agar kotoran plastisin tidak menempel di lantai, kemudian menyediakan air untuk mencuci tangan dan lap tangan.

Guru menyediakan benda konkrit untuk di perlihatkan kepada anak, lalu guru menjelaskan tentang benda tersebut dan mempraktekan cara pembutannya, kemudian anak anak membuatnya tanpa mengggunakan cetakan. Namun hasilnya masih banyak anak yang belum tuntas dalam pembentukannya, guru memberikan motivasi dan semangat pada anak khususnya pada anak yang belum menyelesaikan kegiatan tersebut.

Peneliti melakukan perbaikan pada siklus II dengan cara peneliti memperbaiki metode pembelajarannya, agar lebih menarik perhatian anak terhadap guru sehingga mempengaruhi hasil belajarnya, guru mengulang- ulang dalam proses cara pembutan bentuk bulan dan bintang, sebelum itu guru mengajak anak menyanyi dan bertepuk semangat agar anak lebih semangat dan fokus kepada guru.

Setelah di lakukan pada siklus II menunjukan adanya perubahan pada anak dalam proses pembelajarannya terbukti anak lebih semangat dan lebih fokus terhadap pembelajarannya, dan anak sudah mampu untuk membentuk sendiri sesuai apa yang di perintahkan oleh guru. Anak banyak yang sudah berkembang dalam perkembangan motorik halusnya dengan pencapaian indikator yang di buat oleh guru seperti membuat lingkaran/ bulat, membuat lengkung kanan/ kiri. Dan gerakan manipulatif.

Langkah- langkah pembelajaran oleh peneliti berjalan dengan lancar, berdasarkan hasil penelitian yang telah di laksanakan bahwa hasil penelitian pada siklus I mendapatkan presentasi $44,4 \%$ yang mencapai sudah tuntas dengan kriteria BSH 3 anak dan BSB 1 anak, yang belum mencapai ketuntasan yaitu 5 anak presentasi 55,5\% dengan kriteria BB 2 anak dan MB 3 anak.

Pada siklus II mengalami peningkatan yang sangat signifikan dengan mendapatkan presentasi $77,7 \%$ dengan kriteria BSH 3 anak dan BSB 4 anak, namun yang belum tuntas terdapat 2 anak $(22,2 \%)$ dengan kriteria MB.

Maka penulis menyimpulkan bahwa setelah di gunakannya media plastisin untuk mengembangkan motorik halus anak didk kelompok B di Tk Al Firmansyah Cikande selama pembelajaran di lakukan pada siklus I dan siklus II dapat meningkatkan perkembangan mtorik halus anak didik pada pembelajaran dengan di peroleh melalui pengamatan terhadap hasil kegiatan anak didik pada tiap siklusnya menunjukan hasil yang baik.

\section{KESIMPULAN DAN SARAN}

\section{Kesimpulan}

Berdasarkan hasil penelitian yang penulis lakukan maka dapat di simpulkan bahwa penggunaan media plastisin dapat meningkatkan perkembangan motorik halus anak di Tk Al Firmansyah dengan hasil sangat memuaskan. Adapun hasil perkembangan motorik halus siswa pada pra tindakan mencapai $22,2 \%$ dengan kriteria BSH 1 anak dan BSB 1 anak, dan yang belum mencapai ketuntasan yaitu 7 anak dengan kriteria BB 6 anak dan MB 1 
Nia Kurniasih, Destri Astrianingsih, dan Iis Sholehah: Penggunaan Plastisin Untuk Meningkatkan Perkembangan Motorik halus Anak Usia Dini kelompok B di Tk Al Firmansyah

anak, dari setiap siklusnya mengalami peningkatan yaitu siklus I mencapai 44.4\%.dengan kriteria BSH 3 anak dan BSB 1 anak, dan siklus II mengalami peningkatan yaitu $77.7 \%$.dengan kriteria BSH 3 anak dan BSB 4 anak, peningkatan dari siklus I ke siklus II yaitu $33,3 \%$, maka hasil penelitian yang di peroleh lebih dari kriteria ketuntasan nilai yang di tentukan yaitu $75 \%$.

\section{Saran}

Berdasarkan penelitian Tindakan kelas yang telah di laksanakan maka penulis ajukan beberapa saran. Saran tersebut di ajukan kepada penentu kebijakan. Pelaksana kebijakan dan peneliti.

1. Terhadap pihak sekolah

Di sarankan membuat kebijakan kesejahteraan bagi anak didik dan Pendidikan yang memiliki kreatifitas tinggi dan memiliki motorik halus yangbaik dalam kegiatan belajar mengajar bagi anak usia dini seperti menggunakan berbagai media selain strategi dan metode pembelajaran yang dapat memudahkan guru maupun siswa dalam mencariinovasi dan kreasi. Memberikan fasilitas dalam pembelajaran seperti media Pendidikan.Sarana prasarana yang lengkap agar dapat di gali potensipotensi anak didik secara maksimal.

2. Terhadap anak didik

Harus sering di latih dalam pengembangan motorik halusnya, salah satunya dengan menggunakan media plastisin agar perkembangan motorik halusnya terus semakin meningkat.

3. Terhadap peneliti

Sebaiknya menindak lanjuti penelitian secara continue dengan selalu berfikir kreatif dan inovatif dalam menciptakan pembelajaran yang baik dan menyenangkan bagi anak didik khususnya bagi anak usia dini sehingga menjadikan mutu peserta didik dan pembelajaran lebih efektif dan bermanfaat bagi generasi selanjutnya.

\section{DAFTAR PUSTAKA}

Masitoh. (2011) .pengertian pendidikan dan hakikat pendidikan di taman kanak-kanak.

Hartati (2012) Pendidikan Taman KanakKanak, Jakarta: Universitas

Imam musbikin (2012) Tumbuh Kembang AnakJogjakarta, flash book.

Igrea suswanto (2012) asik bermain plastisiin Jakarta,andi publisher.

Lilis krisnawati (2008) kegiatan bermain plastisin, Jakarta :bumi aksara.

Sumantri.(2011). Perkembangan motori halus anak. Lampung Darussalam press.

Suharismi.A.(2015). Penelitian Tindakan kelas. Jakarta: RinekaCipta.

Un. B. Hamzah. El. Al.(2011). Menjadi Peneliti PTK Yang Professional. Jakarta: PT. Bumi Aksara. 